\title{
Research on Risk Management of International Convention and Exhibition Industry
}

\author{
Zhiming Mo \\ Chongqing City Management College, Chongqing 401331
}

\begin{abstract}
Key words:International exhibition industry; Risk management;Current situation
\end{abstract}
\begin{abstract}
The rapid development of the economy and the further opening up to the outside world, as well as the country in the industrial structure adjustment continued to force, the exhibition industry ushered in the development of the spring. Every industry in the process of rapid development will encounter problems, and faced with no experience can learn from the plight. Opportunities and risks are always co-exist, in the management process if the risk can be effectively grasp, then the development of enterprises will be flourishing, on the contrary will go to a dead end. In this paper, the risk management of international exhibition industry for a brief description of the current situation.
\end{abstract}

Exhibition as a special major economic and trade activities, people, logistics, information flow is highly concentrated, is a risk-sensitive industries. Exhibition risk refers to the impact of exhibitors, professional visitors, related media and other stakeholders on the exhibition of confidence or disturb the exhibition organizers continue to normal operation of the unexpected events, exhibition work in the security risks long way to go.

\section{Related concepts and definitions}

Exhibition activities refers to the organizers through the planning, organization, in a certain time, space range of various exhibitions, theatrical performances and other group activities. Through the definition can be seen that the exhibition has several characteristics. First, in order to achieve a certain goal. Followed by a certain time and space. Moreover, there are various activities in the process of exhibition, there is a planned system of works.

Exhibition industry risk refers to any unforeseeable or unpredictable event that hinders the normal operation of the activity. Corresponding organizations and individuals if the lack of timely understanding and correct treatment, will certainly cause harm to organizations and individuals, characterized by sudden, harmful, urgent and uncertain. The exhibition industry risk management, it refers to the activities of the exhibition unpredictable risk events planned and prepared to monitor, trying to spread the event, loss and negative impact to a minimum.

\section{Research on the Risks of Convention and Exhibition Industry Abroad}

Foreign exhibition industry developed countries of the exhibition industry theory system is more mature, the research on the risks and insurance of exhibition industry is mainly focused on three aspects: risk assessment and management, underwriting insurance and insurance operation mechanism of exhibition industry.

First, the exhibition industry risk assessment and management research. Risk assessment and management of exhibition exhibits are defined as a tool for planners and venue managers to define risk threats as a collection and to systematically quantify and rank the risks within the collection ". Risk assessment and management of the exhibition hall is conducive to risk identification and resolution, through wise risk decision-making, enhance risk accountability, enhance public service capabilities, protect the people, the government's property and interests. Gonzalez and Gloria have proposed "the potential loss, damage risk and insurance claims forecast for the underwriting of high value art in transportation and exhibitions, challenging organizers and professional risk assessment". Use Garnet Muething scholars study the Canadian museum of nature such as risk assessment 
method is used to prevent risks, according to the severity of the risk and risk quantification and sorting, the distribution of the effective risk management of resources.

Second, the insurance industry for the exhibition industry aspects of the study. The BIE requires commercial insurance companies to provide insurance for construction and installation projects, property insurance, comprehensive personal injury insurance and comprehensive liability insurance for participating governments and international organizations. The design of comprehensive liability insurance for the World Expo in Japan Has a certain uniqueness and innovation, mandatory requirements of the exhibition organizers to insure the insurance, to achieve a variety of responsibility for risk management, to ensure that the interests of the public to visit and reduce the social impact.

Thirdly, it studies the insurance operation mechanism of exhibition industry. In the countries and regions where the insurance industry of foreign exhibition industry is relatively mature, the convention and exhibition industry risk and insurance systemization is realized for the convention and exhibition activities through government supervision and industry associations. For example, the North America and Western Europe more mature exhibition market, exhibition business risk management and insurance awareness are very active, especially for the exhibition during the responsibility risk. The government and industry associations require group exhibitors to arrange Comprehensive Liability Insurance (CGL) for exhibition activities and provide the corresponding risk management and legal services.

In summary, the international exhibition industry risk research focused on the exhibition industry insurance at a single point of view of individual or case studies, has not yet formed a large-scale and systematic practice of operation. These practices and research achievements in developed countries have accumulated valuable experience for the study of the development of exhibition industry insurance in China, and provide a good theoretical basis and research ideas for this project.

\section{The risk of international exhibition industry}

Modern exhibition industry in the international development of nearly three hundred years of history, the exhibition industry risk types, the current international consensus reached are:

3.1Hardware risk and software risk. Hardware risk mainly refers to the risk of the existence of hardware in the process of exhibition activities, such as leased premises, infrastructure of the city and facilities of the steel structure and so on.

Relative to hardware risk, software risk is mainly in the management of the problem. Organizational capacity of the organizers, professional staff and high level of service and so on.

3.2Macro and micro aspects. The macro aspects of the risk is mainly for the area in terms of the host area's infrastructure level, the government departments for the exhibition activities support, the level of economic development and local industrial advantages and so on.

Microcosmic is mainly reflected in the organizers themselves, from the marketing point of view, exhibition is an effective way of marketing. The marketing activities carried out in the process, not just the product is well known by the public, on the other hand there are the organizers service.

3.3Economic Risks and Social Risks. Economic risk is due to the objectives set by the exhibition activities, as well as a series of early investment. For the financial risks can be understood from the financial aspects of financial management. In the exhibition activities, the organizers will input and output of the activities of the analysis, one of the high and low rate of return for the potential risk management, risk reduction, return will have a certain guarantee.

The social risk of exhibitions refers to the negative impact of the activities brought about by the relevant aspects, such as the impact of the price of the city, the impact on traffic and so on.

\section{The Main Measures of Risk Management in International Convention and Exhibition Industry}

4.1The establishment of exhibition risk management early warning mechanism. Exhibition risk management in advance to prevent, do the preparatory work in advance. Each exhibition organizer 
does not want to have risk events in their own exhibitions, therefore, we must have a sound risk warning mechanism to be able to risk events may be evaluated, forecasting, in order to develop a response to the risk program. In the management and prevention of exhibition risk, exhibition organizers usually adopt the following methods: establishing the exhibition risk management committee, formulating the contingency plan, and do exhibition staff training within the organization and so on.

\subsection{Develop a scientific risk management strategy}

\subsubsection{To the interests of customers first}

When the risk occurs, the organizers of the exhibition exhibitors, the audience, especially the interests of the majority of exhibitors in the first place, and clearly convey their attitude to deal with the accident and the responsibility of exhibitors, help to effectively control the risk Further deterioration.

\subsubsection{Master the initiative of foreign information dissemination}

When the risk occurs, the exhibition organization should immediately become the first source of information center, the initiative for the exhibitors, spectators and the media to provide background information on the accident, to grasp the initiative to publish information. In addition, do not publish inaccurate information, not the risk of the causes and consequences of lack of basis for speculation. All sensitive issues must be carefully discussed at the decision-making level, the spokesman issued by the external information to a unified approach to risk management.

\subsubsection{Implementation of a unified action program}

In the exhibition risk management, whether internal communication or external communication, should be conducive to the implementation of a unified action program. Specific performance in the following four aspects: unify the risk management awareness in all the exhibition members, formulate and implement the exhibition risk early warning mechanism, when the risk occurs, unified the attitude of dealing with risks and external communication caliber, process the action plan.

\subsubsection{Implementation of public relations exhibition risks}

We should strengthen the media management, correctly play the role of the mass media, do a good job in risk communication programs. Through the means of public relations so that the negative impact of risk to a minimum, and thus enable the organization to get rid of the risk to re-establish a good reputation and image. When the exhibition brand encounters sudden risks and so on, the risk of public relations in resolving market risks, restore brand image, stable exhibition market, with advertising and other forms of communication unparalleled role, which in practice has been verified.

4.3Carry out the details of exhibition risk management. Exhibition risk management, prevention is the key, for the potential risk to be a comprehensive consideration, usually people only take into account the conventional risk, unconventional risk for the unconscious was ignored.

\subsubsection{Site facilities}

International exhibition industry is undergoing rapid development process, the problems faced in risk management come from many aspects. From the hardware point of view, mainly in the corresponding facilities and equipment imperfect. The number of accidents also proved that the collapse of the building is a larger security risk. In the exhibition venue, in addition to buildings there are a lot of advertising and the corresponding advertising facilities, advertising facilities will be affected by the natural environment, there was no electrical accident in the event of the exhibition. Exhibition site selection, usually speaking, the choice of venue and their activities to match the size, and to leave some room for expansion, to avoid the phenomenon of overcrowding. When the crowd focused on the publicity effect to maximize, but the risk at this time also reached the maximum. Some of the exhibition activities for the safety of exports, escape route is not a reasonable plan, safety instructions marked inconsistent with the relevant provisions of the stairs, channels and related prompts set unreasonable aspects.

\subsubsection{Public works risk}

Public works mainly refers to the city's public infrastructure. On the electrical side, the problem 
lies in the management of power system security. According to past experience, in the exhibition activities in the power of the risks mainly in the fire, electric shock, power supply disruption. As the exhibition area is large, complex lines, in terms of manpower is usually the maximum protection. In the area of communications, it is necessary to take into account the risk of infrastructure damage caused by other risks such as fires and collapses. In addition, it is not fully taken into account their own problems, such as high traffic in a short time the case, the emergence of the line congestion and paralysis.

\subsubsection{Natural risk management}

Different regions have different types of natural risks, such as coastal typhoons, heavy rain, high temperature. North more cold, snow and ice. From the time point of view, there are summer haze thunder and lightning. However, in the exhibition in progress, due to various reasons, the intensity of the weather will be reduced. For the concern of the uncertain events to timely access to appropriate information for the exhibition decision-making pave the way, in some cases to take the initiative and have departments to communicate. Natural disasters will have a chain reaction, the preparation of a variety of situations to be probabilistic analysis, and depending on the loudness of the corresponding preparation.

\subsubsection{Social environment.}

Social environmental management problems are mainly site maintenance, crowd gathering, law and order, goods, food and on-site environment and so on. The current management of social and environmental risks for the lack of estimates, such as short-term traffic is too large, more than infrastructure affordability. The crowds will also have some impact on the exhibits.

\section{Conclusion}

The paper studies the performance and problems of risk management mechanism in foreign exhibition industry, analyzes and draws lessons from the successful experiences of developed countries and regions in the risk of exhibition industry, sums up the practical experience of international advanced exhibition industry insurance operation mode and explores the meeting and exhibition of society and stakeholders Industry risk of the market-oriented operating path, is China's exhibition industry healthy and rapid development of the only way.

\section{project stage research. Project number: 2015YBJJ030.}

About the author: Mo Zhiming, born in April 1976, master, associate professor, Chongqing city management college exhibition professional teachers. Research direction: exhibition economy, occupation education.

Papers Project: This paper is the result of 2015 Chongqing social science planning

\section{References}

[1] DU Hua. Risk prevention and management of exhibition activities in the study [J]. Modern economic information, 2015 (24).

[2] Niu Di. Exhibition of economic development status and risk management [J]. People's Forum, 2015 (12).

[3] Graham Chandler. Collections Risk Assessment: Leading the Way [J], Muse, 2006.10.

[4] (US) Solomon Huebner, etc. Property and Liability Insurance (fourth edition), Chen Xin, etc. [M]. Beijing: China Renmin University Press, 2002.

[5] Waller, RR.Cultural Property Risk Analysis Model: Development and Application to Preventive Conservation at the Canadian Museum of Nature [J] .ActaUniversitatis Gothoburgensis, Gbteborg, 2003.

[6] Gonzalez, Gloria. Travelling art exhibits require careful risk assessment: Expert [J] .Business Insurance, 2008. 